\title{
Evaluating and Enhancing the Operational Performance of Public Bus Systems Using GIS-based Data Envelopment Analysis
}

\author{
Yaser E. Hawas, Md. Bayzid Khan, Nandita Basu \\ United Arab Emirates University
}

\begin{abstract}
In this paper, the baseline performance level of Al Ain Public Bus Service is evaluated using Data Envelopment Analysis (DEA) based on some selected input (travel time per round trip, total number of stops, total number of operators, total number of buses) and output (daily ridership and vehicle-kilometer) variables. Two types of scenarios were developed and tested. The first set of scenarios aimed at investigating the possibility of reducing the operating cost while maintaining the same performance levels (efficiency and effectiveness) for the routes. The second set of scenarios was used to demonstrate how the baseline performance levels can be improved by slightly altering the route alignment (and subsequently input and output variables). Sensitivity analysis was then conducted to measure the efficiency and effectiveness of each route. Conclusions on how the transit authority can reduce daily operating hours while maintaining the existing performance level are made. Also, suggestions are presented on how to improve the overall performance level of the bus service by changing some route characteristics.
\end{abstract}




\section{Introduction}

Public transit systems are essential parts of the modern urban life. In some countries such as the United Arab Emirates (UAE), where such mode of transport is relatively new and people can easily avail private vehicles, it is quite essential to operate public bus service efficiently and effectively to make this mode choice more favorable to private vehicles.

Public bus services should operate efficiently and effectively, from both demand and supply perspectives. Although the general terminologies of "efficiency" and "effectiveness" may seem to be closely related, these two measures are required to be considered separately in public transit system (Hatry 1980; Chu et al. 1992). As for effectiveness, people should feel that buses are available to meet their daily travel demand with lower cost. As such, effectiveness can be measured by service utilization (ridership), service quality, and accessibility to the service (Fielding et al. 1985). As for efficiency, the service authority typically aims at minimizing the operational cost without hampering the daily travel demand of the people. As such, efficiency measures describe the relationship between resource inputs and produced output and includes indicators of overall cost efficiency, labor utilization, and vehicle utilization (Fielding et al. 1985). Both efficiency and effectiveness were used as measures within the DEA context. In fact, much of the reported literature has used the two measure types to evaluate transit system performance within the DEA context (Chu et al. 1992; Karlaftis 2004; Lao and Liu 2009).

It is important to seek optimum solutions to operation parameters (e.g., schedules, frequencies) without jeopardizing the necessities of operation (meeting demands while achieving the highest levels of customer satisfaction). Balancing both sides of demand and supply issues is not an easy task and usually entails reduction of service quality to attain more reasonable levels of expenditures. That is, minimizing operation and maintenance costs (input) usually comes at the expense of a reduction in ridership. Similarly, maximizing throughput (ridership) is usually associated with higher operational cost.

Commonly, the goal of transit system authorities is to provide as much efficient and effective service to users regardless of the operating costs (Chu et al. 1992; Karlaftis 2004), especially during the first few years of operation until the systems are mature enough and are well reputed to attract traditionally private car users. This is commonly coupled with continuous assessment of performance, and even setting benchmarks and to improve service (Park and Kamp 2004). In economics, performance assessment or efficiency are measured by comparing levels of output 
to input (Cooper et al. 2004; Fare et al. 1994; Nash 2006; Barnum et al. 2007). The assessment normally starts with identifying the important operation characteristics (inputs) and the targeted outputs. In public transit systems, multiple outputs are produced by multiple inputs (Barnum et al. 2007), and it is difficult to aggregate all input and output variables into a single scale to measure the performance levels. Data Envelopment Analysis (DEA) provides an innovative approach to resolve such difficulties to measure the relative efficiency of the system (Barnum et al. 2007).

This paper aims at developing and presenting an approach using the DEA method that can be used to investigate the operational characteristics of service, identify drawbacks in operation through GIS-based data analysis, and provide a framework that can be adopted to mitigate such deficiencies in a cost effective manner. The approach is demonstrated through the newly-introduced bus service in Al Ain in the UAE.

This paper builds upon earlier data collection for the study of evaluating public bus services in Abu Dhabi and Al Ain in the UAE (RTTSRC 2010). The paper describes the data collection methodology and the obtained results aiming at evaluating the performance of Al Ain public bus service from an operational perspective. This entails analyzing the field data of all bus routes in Al Ain. Two types of scenarios were developed and tested. The first set of scenarios aims at investigating the possibility of reducing operating cost while maintaining the same performance levels (efficiency and effectiveness) for the routes. The second set of scenarios was used to demonstrate how the baseline performance levels can be improved by slightly altering the route alignment (and subsequently input and output variables). Sensitivity analysis was then conducted to measure the efficiency and effectiveness of each route.

\section{Literature Review}

A number of studies were conducted to identify the key performance indicators of public transit services based on the goals and objectives of the authorities (Tomazinis 1977; Gilbert and Dajani 1975; Fielding et al. 1978; Meyer and Gomez-lbanez 1981; Forkenbrock and Dueker 1979; Bly and Oldfield 1986; Cervero 1984). These studies used relatively variant performance indicators. As such, these studies cannot be used to reach a generalized conclusion (Benjamin and Obeng 1990; Karlaftis 2004). This has led some researchers to conclude that it may be necessary to use 
a more concise yet reliable set of indicators to describe the public transit system performance (Karlaftis 2004).

Anderson and Fielding (1982) and Fielding et al. (1985), in an effort to reduce the number of indicators, used factor analysis to reduce 48 performance indicators to 7 measures. Benn (1995) selected a number of inputs and categorized these into five broad groups to determine the evaluation standards: route design, schedule design, economics and productivity, service delivery and monitoring, and passenger comfort and safety. The study concluded that service quality and operating cost were the most two important factors for the users to evaluate the overall service effectiveness.

In general, in transit systems, labor, capital and energy are used as inputs, while efficiency measures such as vehicle kilometers, seat kilometers, or passenger kilometers are used as outputs (Fielding et al. 1985; De Borger et al. 2002). Karlaftis (2004) further defined each of these input levels using quantitative measures. For example, the labor input factor is defined as the total number of employees (including operators, maintenance staff, and administrative personnel). Capital is defined as the total number of vehicles operated by the system. Energy is defined as the total annual amount of fuel used by the system (in gallons). Vehicle-miles and passenger-miles were used as the output variables to measure the efficiency and effectiveness of U.S. transit systems. Sanchez (2009) and Sakano et al. (1997) used the number of full-time workers, fuel consumption, and number of operating buses as the input variables.

Sanchez (2009) used a number of output variables such as vehicle kilometers, seating capacity, service hours, number of passengers, and average age of the fleets to evaluate bus service performance of Spanish transport systems. Lao and Liu (2009) evaluated the performance of bus lines from the operational and spatial aspects. Operating time, round-trip distance, and number of stops were used as inputs to measure operational efficiency. Total number of bus users, population age 65+ years, and number of persons with disabilities using the service were used as the inputs to measure spatial effectiveness. In both cases, total annual number of passengers was used as the output.

There are two approaches to assess the performance of the transit system: either by comparing to standards or by measuring and assessing the relative efficiencies if no standards are available. As there are no standards available to benchmark service in the UAE, the second approach was chosen to assess bus service performance. There are several methods to measure and assess performance. The methods can 
be classified as parametric and non-parametric tests. Pucher (1982) used correlation coefficients to measure performance. Karlaftis et al. (1997) applied a t-test technique to measure whether there was a significant change in the performance of transit system of two models. Boschken (2000) and Obeng and Azam (1995) used the ordinary least square methods (OLS) to calculate the production and cost functions, respectively. All of these are parametric techniques to measure the performance of a transit system.

These parametric techniques entail assumptions on the functional forms of the production or cost functions. This motivated researchers to use non-parametric approaches that entail fewer assumptions (Sanchez 2009). The non-parametric technique known as Data Envelopment Analysis (DEA) has been widely used to measure the efficiencies and effectiveness of public transit systems (Zhu 2003). DEA was used in many studies to evaluate the public transit service performance (Cowie and Asenova 1999; Pina and Torres 2001; Kerstens 1999; Odeck and Alkadi 2001; Boil'e 2001 and Nakanishi and Norsworthy 2000). Chu et al. (1992) developed a single index for measuring service efficiency as well as service effectiveness of public transit agencies using DEA. Barnum et al. (2008) evaluated the performances of 46 bus routes of U.S. transit systems using the DEA method.

DEA is a non-parametric approach and linear programming technique to measure relative efficiencies of a set of peer units called Decision Making Units (DMUs). This is based on the original work of Farrel (1957) and was later popularized by Charnes et al. (1978) as the CCR model. The CCR model is fairly inflexible in the sense that it assumes constant returns to scale in its production possibility set (Karlaftis 2004). Later, Banker et al. (1984) developed an efficiency frontier structured by both constant and decrease returns to scale. The underlying assumption is that each DMU requires certain resources or inputs to produce its goods or services (outputs). It is used to empirically measure productive efficiency of DMUs by comparing it to the best practice of a DMU or combination of DMUs (Lao and Liu 2009). This model is called the BCC model.

\section{DEA Model}

DEA is a linear programming-based technique for measuring the relative performance of organizational units where the presence of multiple inputs and outputs makes comparisons difficult. Such organizational units are referred to as DMUs. In this work, DMU is the term used to refer to bus routes. Extensive literature and tuto- 
rials on DEA can be found in Emrouznejad (2001). DEA models can be classified based on their orientation into two types: input- and output-oriented models. The inputoriented models minimize the inputs while producing at least the observed output levels. The output-oriented models improve the performance of a DMU by maximizing its outputs, while consuming at most the observed input levels (Forsund 2001).

The type of model orientation to use depends on the objective of the decision maker. If the objective is to minimize the cost of service, the input-oriented DEA model is chosen. On the other hand, if the objective is to maximize the output level, the output-oriented model is chosen. In this study, the output-oriented BCC model was chosen to maximize ridership (number of passengers). In the UAE, the public transit system was recently introduced with the objective of offering services regardless of operational cost. Another reason to choose the BCC model is that it employs a Variable Return to Scale (VRS) assumption, which means that efficiency may increase or decrease with a change in size in input or output. Mathematically, VRS suggests that the estimated production frontier can pass anywhere relative to the origin in input-output space (Lao and Liu 2009).

Mathematically, the BCC model (Banker et al. 1984) can be written as follows:

$$
\begin{array}{ll}
\operatorname{Max}_{u, v} \quad \theta_{k}=\frac{\sum_{m=1}^{M} u_{m} y_{m k}}{\sum_{n=1}^{N} v_{n} x_{n k}} \\
\text { subject to } \quad \frac{\sum_{m=1}^{M} u_{m} y_{m j} \leq 1 \quad \forall j}{\sum_{n=1}^{N} v_{n} x_{n j}} \\
\sum_{n=1}^{N} v_{n} x_{n k}=1 \\
& u_{m}, v_{n}, y_{m j}, x_{n j}>0 \quad \forall m, n, j
\end{array}
$$

Where,

$j:$ Index of decision making unit (DMU), $j=1, \ldots, j$

$n:$ Index of input, $n=1, \ldots, N$

$m$ : Index of output, $m=1, \ldots, M$

$x n j:$ The $n^{\text {th }}$ input for the $j^{\text {th }} \mathrm{DMU}$

$y m j$ : The $m^{\text {th }}$ output for the $j^{\text {th }}$ DMU 
um,vn : Non-negative scalars (weights) for the $m^{\text {th }}$ output and the $n^{\text {th }}$ input $\theta_{k}:$ Efficiency/Effectiveness ratio of $\mathrm{DMU}_{k}$

The targeted $\mathrm{DMU}$ (of a given evaluation) is designated as $\mathrm{DMU}_{\mathrm{k}}$. The $\mathrm{BCC}$ model (Eq. 1) maximizes the ratio of weighted outputs to the weighted inputs. The weights $u_{\mathrm{m}}$ and $v_{\mathrm{n}}$ are the decision variables. These weights are changed until the ratio (of the weighted outputs to the weighted inputs) is maximized for the target DMUk, while same weights are applied to all DMUs. The value of the ratio, $\theta$, in (1) is referred to as the efficiency/effectiveness score of DMUk, where $0 \leq \theta \leq 1$. For a fully efficient $D M U$, the value of $\theta$ is 1 . It is to be noted that the weights are the decision variables and that the values of inputs and outputs are the actual observed values. Constraint (3) ensures the DEA model's Variable Returns to Scale (VRS). Constraint (4) imposes non-negativity restrictions for the weights.

\section{Al Ain Bus Services}

Public bus service has been operated in the UAE for more than a decade. The Department of Transport (DOT) in the Emirate of Abu Dhabi conducted major upgrades to the service (new routes, buses, etc.) in Al Ain around 2009 and 2010. Currently, there are eight routes operating in the city. Figure 1 illustrates the paths of the eight inter-city bus routes in Al Ain. This paper uses the GPS-based collected data to illustrate how the DEA model, combined with a GIS analysis technique, can be used to enhance the operational efficiency of the bus routes.

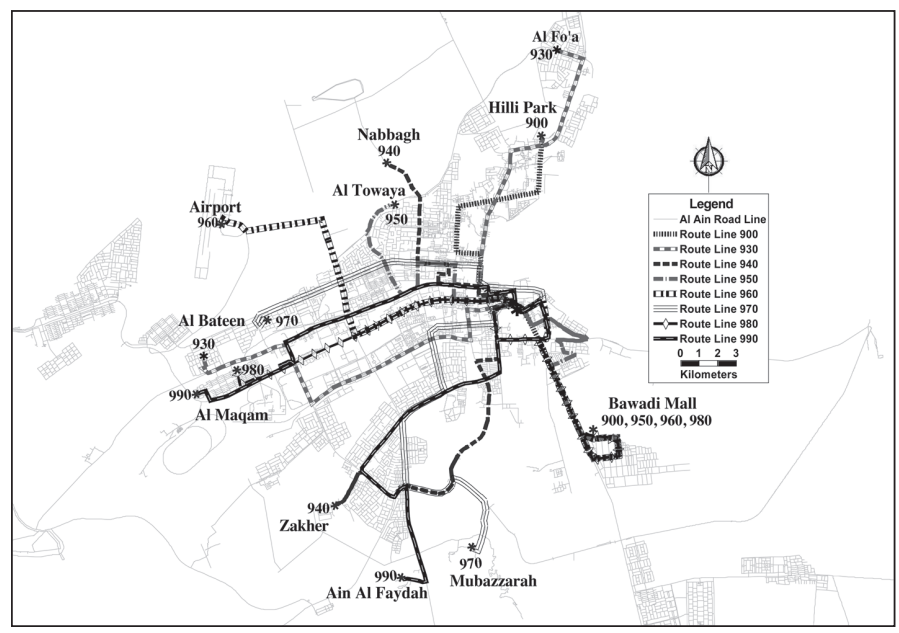

Figure 1. Paths of the inter-city bus routes in Al Ain city 


\section{Methodology}

\section{Data Collection and Analyses}

Extensive surveys were carried out on all eight routes for three different peak periods (7-9 AM, 12-2 PM, and 5 to 9 PM) daily, over a one-week duration. Three types of surveys were used: a user opinion survey, an operator survey, and a log survey (RTTSRC 2010). Only the log survey data were used in this paper to measure the performance level of the Al Ain bus service. In this survey, the locations of all bus stops (latitude and longitude data) were collected using GPS devices. The numbers of passengers boarding/alighting at each bus stop were counted manually and inserted into the same log survey form.

The collected data were used to estimate the total number of stops on each route direction and their exact locations, route lengths, average number of passengers per day on each route, travel time of each trip for all routes, operating hours, total number of buses operated on each route, total number of operators working on each route, user's concerns about each route, etc.

\section{Selection of Input and Output Variables for the DEA Model}

As previously indicated, labor, capital and energy measures are the most commonly-used inputs in literature. On the other hand, vehicle kilometers, seat kilometers, or passenger kilometers are the most commonly-used outputs (De Borger et al. 2002). Because of the absence of the actual cost data for labor, fuel, and other operational expenses, many researches have used different input variable sets to represent the cost variables (Karlaftis 2004; Lao and Liu 2009). Based on the types of input and output variables, three approaches were identified in the literature to use DEA to measure the efficiency and effectiveness of a transit system. The approaches are 1) separate sets of input and output variables (Chu et al. 1992); 2) separate input but same output variables (Lao and Liu 2009); and 3) same input but separate output variables (Karlaftis 2004).

As an example for the separate inputs separate outputs approach, Chu et al. (1992) used annual vehicle operating time, annual maintenance expenses, annual administrative expenses, and annual other expenses as input variables and annual revenue vehicle hours as the output variable to measure efficiency. They used urbanized area population density, proportion of households with automobile, annual revenue vehicle hours, and annual financial assistance per passenger as the input variables and annual unlinked passenger trips as the output variable to measure effectiveness. 
As an example of separate inputs and same output approach, Lao and Liu (2009) used operation time, round-trip distance, and number of bus stops as the input variables for measuring operational efficiency. They used number of commuters using buses, population age $65+$, and persons with disabilities as the input variables for effectiveness measurement. They used number of total passengers as the output variable for measuring both efficiency and effectiveness of the transit system.

As an example of same input but separate output variables, Karlaftis (2004) used total number of employees, total annual amount of fuel used by the system, and total number of vehicles as the input variables to measure both efficiency and effectiveness. The output variables of vehicle-miles and ridership were used to measure the efficiency and effectiveness, respectively.

Due to the unavailability of detailed cost and population data, the third approach was followed in this study. Earlier studies indicated that cost of operating a bus route is related to four specific measuresy: number of stops (Lao and Liu 2009), number of operators, number of operating buses (Sanchez 2009), and average travel time. As the objective of the study was to measure the relative performance of the bus routes, these four variables were selected as the input variables representing the broad cost category for the DEA model proposed in this paper. For example, number of operators is an implicit representation of labor cost; number of operating buses is an implicit representation of capital cost, and number of stops together with average travel time will both implicitly represent fuel cost.

The output of a transit system can be quantified using vehicle-kilometers and/ or passenger boarding (Karlaftis 2004). The vehicle-kilometers variable is related to the service produced or efficiency. Passenger boarding is more related to the consumption of services; more passengers indicates more utilization, more consumption of service, or better effectiveness. Therefore, vehicles-kilometers and passenger boarding or ridership data were selected as output variables to measure transit service efficiency and effectiveness, respectively (Karlaftis 2004; Fielding 1987). The four mentioned input variables were used to measure both efficiency and effectiveness of the Al Ain transit system.

All field data were prepared in the form of round-trip data per day to provide consistency. The DEA model used in this study has four input and two output variables, as shown in Table 1. The DEA model in this case has eight DMUs (routes). It is to be noted that some data were extracted from DOT records: total number of trips per day on each route, number of vehicles operating on each route, and number of operators. Other variables such as total travel length and travel time for 
each round trip, total number of stops, and average daily passengers were obtained from the field survey data. Table 1 shows the selected inputs and output variables of the baseline (current) operating conditions (for the DEA model).

\section{Table 1. Input and Output Variables of Baseline (Current) Operating Conditions (for DEA Model)}

\begin{tabular}{|c|c|c|c|c|c|c|}
\hline \multirow{2}{*}{$\begin{array}{c}\text { Route \# } \\
\text { (DMUs) }\end{array}$} & $\begin{array}{c}\text { Average } \\
\text { travel time } \\
\text { per round } \\
\text { trip (hr) }\end{array}$ & $\begin{array}{c}\text { \# of } \\
\text { vehicles }\end{array}$ & $\begin{array}{c}\text { \# of } \\
\text { operators }\end{array}$ & $\begin{array}{c}\text { Total \# } \\
\text { of stops } \\
\text { (round trip) }\end{array}$ & $\begin{array}{c}\text { Total avg. \# of } \\
\text { passengers per day } \\
\text { (effectiveness } \\
\text { measure) }\end{array}$ & $\begin{array}{c}\text { Vehicle-km } \\
\text { (per day) } \\
\text { (efficiency } \\
\text { measure) }\end{array}$ \\
\hline 900 & 2.43 & 6 & 15 & 98 & 3300 & 2016 \\
\hline 930 & 3.20 & 8 & 20 & 126 & 3690 & 3348 \\
\hline 940 & 2.78 & 6 & 15 & 121 & 3973 & 2052 \\
\hline 950 & 2.72 & 6 & 15 & 128 & 2078 & 2124 \\
\hline 960 & 2.45 & 6 & 15 & 91 & 2227 & 2556 \\
\hline 970 & 3.10 & 8 & 20 & 130 & 2384 & 3456 \\
\hline 980 & 3.26 & 8 & 20 & 119 & 4425 & 2304 \\
\hline 990 & 3.85 & 10 & 25 & 147 & 3895 & 3535 \\
\hline
\end{tabular}

DEA is used to measure the efficiency of a system, given the inputs that represent the cost items or operational characteristics and the outputs of the system. If the output variable(s) reflects the efficiency measure (such as vehicle-kilometers per day), then the DEA is actually evaluating the "efficiency" of the bus system. If the output reflects the effectiveness measure (total number of passengers per day), then the DEA is actually evaluating the "effectiveness" of a system. That is, the DEA method is used herein to measure:

1. Effectiveness or cost-effectiveness: total number of passengers per day on each route is the output variable used as the measure for effectiveness - the measure to be maximized.

2. Efficiency or produced service efficiency: vehicle-kilometers per day on each route is the output variable used as the measure for efficiency.

Detailed analyses were conducted on the minimum number of variables to be included. Initially, the analysis was conducted with seven input variables. More input variables will likely reveal that all routes are effective (or efficient). On the other hand, only a few input variables are likely to result in wrong conclusions on the effective (or efficient) routes, as the system cost is represented by only a few variables and ignoring important cost items. By trial and error, the authors con- 
cluded that the used four input variables are the minimum essential ones to be included.

Each of these inputs is used to reflect one of the cost items. Number of vehicles on each route implicitly reflects the capital cost. Number of operators implicitly reflects operators cost. Average travel time and number of stops are intended to implicitly capture on the operational or fuel consumption cost.

\section{Efficiency and Effectiveness Score of Baseline Condition}

The efficiency and effectiveness measures were estimated using a readily-available Microsoft EXCEL macro (Productivity Tools 2005), which uses the same set of equations (Eqs. 1-4) to calculate the efficiency and effectiveness scores. The vehicle-kilometers and total average number of passenger per day were used as the output variables to measure the efficiency and effectiveness of the transit system, respectively. A scale to classify the efficiency and effectiveness scores was used, according to Lao and Liu (2009):

There is empirical evidence to indicate a linear relationship between the inputs and output variable. Carrying out a linear regression analysis between the efficiency measure "vehicle kilometers per day on each route" and the input variables reveals significant linear relationship with an R2 value of 0.98 , and a significant $F$-value of about 135. This justifies the use of the DEA approach as a linear programming approach.

An efficiency and effectiveness score $(\theta)$ equal to 1 means an efficient and effective system. An efficiency and effectiveness score $(\theta)$ between 0.6 and 1 means a fairly efficient and fairly effective system. An efficiency and effectiveness score $(\theta)$ of less than 0.6 means and inefficient and ineffective system. Tables 2 and 3 show the efficiency and effectiveness scores, respectively. The DMUs efficiency and effectiveness scores are classified according to the scale by Lao and Liu (2009).

Table 2. Efficiency Scores of Each Route for Baseline Condition

\begin{tabular}{lccc}
\hline DMUs & Efficiency scores & Return-to-scale & Comment \\
\hline 900 & 1.00 & Increasing & Efficient \\
930 & 0.99 & Decreasing & Fairly Efficient \\
940 & 0.80 & Increasing & Fairly Efficient \\
950 & 0.83 & Increasing & Fairly Efficient \\
960 & 1.00 & Constant & Efficient \\
970 & 1.00 & Constant & Efficient \\
980 & 0.72 & Decreasing & Fairly Efficient \\
990 & 1.00 & Decreasing & Efficient \\
\hline
\end{tabular}




\section{Table 3. Cost-Effectiveness Scores of Each Route for Baseline Condition}

\begin{tabular}{lccc}
\hline DMUs & Cost-effectiveness Scores & Return-to-scale & Comment \\
\hline 900 & 1.00 & Increasing & Effective \\
930 & 0.84 & Decreasing & Fairly Effective \\
940 & 1.00 & Constant & Effective \\
950 & 0.54 & Increasing & Ineffective \\
960 & 1.00 & Increasing & Effective \\
970 & 0.56 & Decreasing & Ineffective \\
980 & 1.00 & Constant & Effective \\
990 & 0.88 & Decreasing & Fairly Effective \\
\hline
\end{tabular}

Based on the scales of the efficiency and effectiveness scores, Table 4 provides a summary in the form of a classification matrix for all routes.

\section{Table 4. Classification of Al Ain Bus Routes According to Efficiency and Effectiveness Scores}

\begin{tabular}{lccc}
\hline & Effective & Fairly Effective & Ineffective \\
\hline Efficient & 900 & 990 & 970 \\
\hline Fairly efficient & 960 & 930 & 950 \\
\hline Inefficient & 980 & - & - \\
\hline
\end{tabular}

It can be observed from the Table 4 that routes 900 and 960 are the most effective and efficient ones. One of the reasons for such high performance may be that these two routes have average demand levels as compared to other routes, but their input variables are the least among the others. As such, the DEA has identified these to be among the most effective routes.

No route is performing inefficiently in Al Ain, but routes 950 and 970 are performing ineffectively. This may be due to the relatively low passenger demands on these routes. The long distance (the geographical extension) that these two routes serve may be another reason for the low number of daily passengers. Route 950 operates between the Bawadi Mall (a major production/attraction commercial zone surrounded by low-income labor accommodation areas) and Al Towaya districts (a relatively high-income residential zone, where the majority of residents prefer to travel via their own private vehicles). In brief, one could argue that one route end is a major production/attraction zone while the other is not. This results in relatively low demands of bus passengers along this route. 
The 950 route can be envisioned to have two parts. The first part (from Bawadi to the city center) is the one highly used, and the second part (from the city center to Towaya) is not effectively used. The first part is mostly used by captive riders (low-income class), as the origin is close to their residence. The second part is mostly used also by captive riders because of the frequent stops that discourage high-income choice riders using the service. Also, with the destination being a highincome residential zone, the demand on this part of the route is relatively small. Enhancing the service on the second part of the route by providing express service to the destination can help attract more choice riders.

Route 970 operates between the Al Bateen East district (a residential zone in the far suburban area of the city) and the Mubazzara district (a tourism and recreational area with very few or no residential accommodations). This may also explain the relatively low passenger demands along this route.

It can be said that the original alignment of these routes did not pay particular attention to the nature of the origin/destination zones. The original alignment of the city bus routes was determined to provide nearly full spatial coverage of the entire city, but not necessarily based on the expectations of the bus passenger demands from/to the various zones. This is evident in the long travel time per round trip (some round trips amount for more than three hours) and the extremely high number of stops (some routes serve more than 100 bus stops), as shown in Table 1.

\section{Experimental Scenarios}

Two types of experimental scenarios were developed and tested. The first set of scenarios aimed at investigating the possibility of reducing operating cost while maintaining the same performance levels (efficiency and effectiveness) for the routes. The second set of scenarios aimed at demonstrating how the baseline performance levels can be improved by slightly altering the route alignment (and, subsequently, the input and output variables). The details of these two sets of scenarios are explained in more detail below.

\section{Scenarios for assessing the impact of operating cost reduction}

Routes 980, 930, and 950 were selected (from the "fairly efficient" group) for further analysis. The three routes exhibit various levels of effectiveness ("effective," "fairly effective," and "ineffective," respectively). Different scenarios were intuitively suggested and developed for further analysis. The objective was to check whether lowering the operating cost may affect the performance level significantly. The 
actual operating cost data were not readily available in monetary value. As such, herein, it is assumed that operating cost is related to the hours of operation. That is, operational cost (increase or decrease) will be affected by a change in operating hours. If, for instance, operating hours are reduced by 20 percent from the current operating hours ( 18.5 hours daily), operational cost will be reduced by the same percentage. Herein, the term "operating hours" refers to the total number of hours for which bus service is provided.

Three separate scenarios were considered here to reduce operating cost. Scenario 1 entails reducing the operating hours on route 980 by discontinuing the service during times where the passenger loading (in any hour) is less than a specific threshold (defined here as 5 passengers per hour). Scenarios 2 and 3 entail reducing the operating hours on routes 930 and 950 , respectively, by discontinuing the service (operation hours) based on the defined threshold. In addition to these individual scenarios, combined scenarios were also considered-for instance, combining scenarios 1 and 2, 2 and 3, etc.

In deciding the trips to be discontinued, the hours that have very little impact on service attractiveness were selected. These hours were specified as those in which very few passengers use the service. The idea here was to eliminate round trips with very few passengers, which will subsequently reduce operating cost and have very little impact on service attractiveness to passengers.

It was found that for 3 hours 25 minutes of overall operating hours (1 round trip for the 980 route), the number of passengers was less than or equal to 5 . Eliminating this round trip on the 980 route schedule reduces the overall vehicle-km per day. Herein, we assumed that the total number of passengers per day reduced by the number of passengers using the bus service eliminated a round trip. Similarly, it was found that a total of 5 hours 15 minutes ( 2 round trips) and 5 hours 30 minutes ( 2 round trips) can be discontinued for routes 930 and 950, respectively.

It was assumed that the changes on one route affect the characteristics and, as such, the performance measures of that route. For example, discontinuing some round trips on route 980 (scenario 1: reducing overall operating hours by 3 hours 25 minutes) affects vehicle-kilometers as well as total daily passengers and, as such, the performance measures (efficiency and effectiveness) of the route. The effect of changing the characteristics of the route (reducing its operating times) may or may not spread to other route performance measures, as will be explained later. The modified values of the output variables for the three individual scenarios are shown in Table 5. It is to be noted that the values of the input variables for these 
scenarios are same as the base condition. The total number of round trips made by each of these three routes $(930,950$ and 980$)$ is 36 per day. Reduction percentages have been calculated based on the number of round trips per day. It was assumed that reducing 1 round trip for route 980 will reduce 2.7 percent of the total operating cost per day for this route.

\section{Table 5. Modified Values of Input and Output Variables for All Scenarios}

\begin{tabular}{|c|c|c|c|c|c|c|c|c|}
\hline \multirow[b]{2}{*}{ Scenario } & \multirow[b]{2}{*}{$\begin{array}{l}\text { Route \# } \\
\text { (DMUs) }\end{array}$} & \multicolumn{4}{|c|}{ Input variables } & \multicolumn{2}{|c|}{ Output variables } & \multirow[b]{2}{*}{$\begin{array}{l}\text { Percentage of } \\
\text { reduction in } \\
\text { operating cost }\end{array}$} \\
\hline & & $\begin{array}{l}\text { Avg. } \\
\text { travel } \\
\text { time per } \\
\text { round } \\
\text { trip (hr) }\end{array}$ & $\begin{array}{c}\text { \# of } \\
\text { vehicles }\end{array}$ & $\begin{array}{c}\text { \# of } \\
\text { operators }\end{array}$ & $\begin{array}{c}\text { Total \# } \\
\text { of stops } \\
\text { (round } \\
\text { trip) }\end{array}$ & $\begin{array}{l}\text { Total avg. } \\
\text { \# of } \\
\text { passengers } \\
\text { per day }\end{array}$ & $\begin{array}{l}\text { Vehicle- } \\
\text { km (per } \\
\text { day) }\end{array}$ & \\
\hline 1 & 980 & 3.26 & 8 & 20 & 119 & 4,416 & 2,240 & $2.7 \%$ \\
\hline 2 & 930 & 3.2 & 8 & 20 & 126 & 3,669 & 3,162 & $5.56 \%$ \\
\hline 3 & 950 & 2.72 & 6 & 15 & 128 & 2,060 & 2,006 & $5.56 \%$ \\
\hline
\end{tabular}

\section{Scenario for improving the performance level}

Strategies to enhance the performance levels of the routes could entail changing route schedules, alignment, frequencies, etc. For the impact of these strategies to be quantified, transit planning tools are commonly used in some sort of "what if" type of studies. Such planning tools are commonly limited by internal assumptions that determine how passenger demand patterns are influenced by these strategies. The validity of such assumptions and the planning parameters represent limitations to argue the validity of these models' results. In this paper, we demonstrate how the DEA model can be used to assess the strategies meant to improve the performance levels.

The performance matrix (Table 4) shows that routes 930 and 950 are the least performing routes. These two routes were selected for further analysis to improve their performance levels.

In general, the public bus routes of Al Ain can be characterized by their excessively long route lengths, ranging between 56 and 102 kilometers per round trip (as measured through the GIS technique). The number of stops or the average travel time per round trip is associated with this route length, i.e., higher travel time or higher number of stops for a longer route length. Furthermore, the number of passengers may not be evenly distributed along the whole route. For example, for route 950, more passengers board to go to the town center from the Bawadi Mall area compared to from the Towaya area (Figure 2). The strategy to enhance the performance 
of these two routes (930 and 950) entails splitting them into four routes (930A, 930B, 950A, 950B). The underlying rationale for developing such a split route scenario is that the long route length might hamper the overall performance level of the transit system.

Figure 2 illustrates the paths of the new split routes. The four new routes coincide with the Al Ain central area. The number of passengers along these new routes was calculated based on the number of passengers boarding/alighting at each bus stop. The route length and corresponding number of stops and average number of passengers per day for these split routes were calculated using a GIS tool. The values of other input variables were split according to the split length ratio of the two initial routes (930 and 950). The vehicle-kilometers (per day) were then calculated. The values of the input and output variables of these split routes are shown in Table 6. It is to be noted that the values of the input and output variables for the other routes were kept as in the base condition.

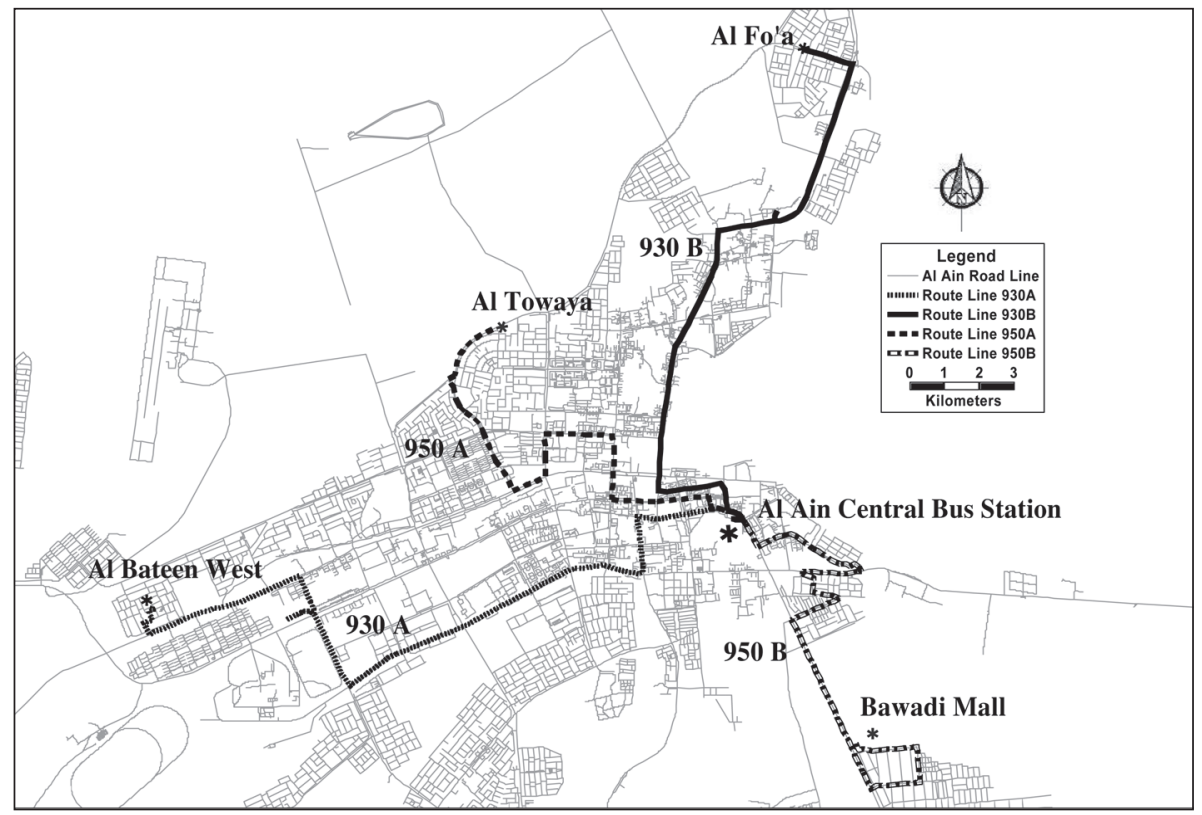

Figure 2. Paths of the split routes 


\section{Table 6. Modified Values of Input and Output Variables for Split Routes}

\begin{tabular}{|c|c|c|c|c|c|c|}
\hline \multirow[b]{2}{*}{$\begin{array}{l}\text { Route \# } \\
\text { (DMUs) }\end{array}$} & \multicolumn{4}{|c|}{ Input variables } & \multicolumn{2}{|c|}{ Output variables } \\
\hline & $\begin{array}{l}\text { Avg. } \\
\text { travel } \\
\text { time per } \\
\text { round } \\
\text { trip (hr) }\end{array}$ & $\begin{array}{c}\text { \# of } \\
\text { vehicles }\end{array}$ & $\begin{array}{c}\text { \# of } \\
\text { operators }\end{array}$ & $\begin{array}{l}\text { Total \# } \\
\text { of stops } \\
\text { (round } \\
\text { trip) }\end{array}$ & $\begin{array}{l}\text { Total avg. } \\
\text { \# of } \\
\text { passengers } \\
\text { per day }\end{array}$ & $\begin{array}{c}\text { Vehicle- } \\
\text { km (per } \\
\text { day) }\end{array}$ \\
\hline $930 \mathrm{~A}$ & 1.8 & 5 & 11 & 69 & 1,476 & 1,872 \\
\hline $930 \mathrm{~B}$ & 1.4 & 3 & 9 & 59 & 2,214 & 1,476 \\
\hline $950 \mathrm{~A}$ & 1.45 & 3 & 8 & 72 & 1,039 & 1,152 \\
\hline $950 \mathrm{~B}$ & 1.25 & 3 & 8 & 58 & 1,039 & 972 \\
\hline
\end{tabular}

\section{Results and Analyses}

\section{Results and analysis of operating cost reduction scenarios}

The DEA model was run again to recalculate the efficiency the effectiveness measures of the individual routes as a result of the above service changes (scenarios). Figure 3 exhibits the efficiency scores for all considered scenarios. As can be seen, routes 930,950 , and 980 exhibit changes in efficiency scores. The efficiency scores of all the other routes remain fixed.

Similarly, Figure 4 illustrates the effectiveness scores of all the routes as a result of all tested scenarios. Figures 3 and 4 clearly illustrate that very little change occurred to the efficiency and effectiveness scores as a result of the service changes. That is, the operating cost could be reduced as a result of the service hour changes while maintaining the same levels of efficiency and effectiveness.

The efficiency and effectiveness classifications remain the same (exactly as in Table 4), similar to the classification of the base condition. Figure 5 shows the deviation of efficiency scores for all scenarios from the base condition. The positive deviation means the efficiency score of the scenarios is lesser than that of the base condition. The maximum deviation (0.054) was encountered for route 930.

The reduction in the service operating hours had a slight effect on the efficiency measure. The reason is that the changes or reductions made in operating hours were not accompanied by significant changes to vehicle-kilometers or number of passengers. The combined scenario $(1,2$, and 3$)$ is the preferred one, as this will reduce the operating hours for all three routes. 


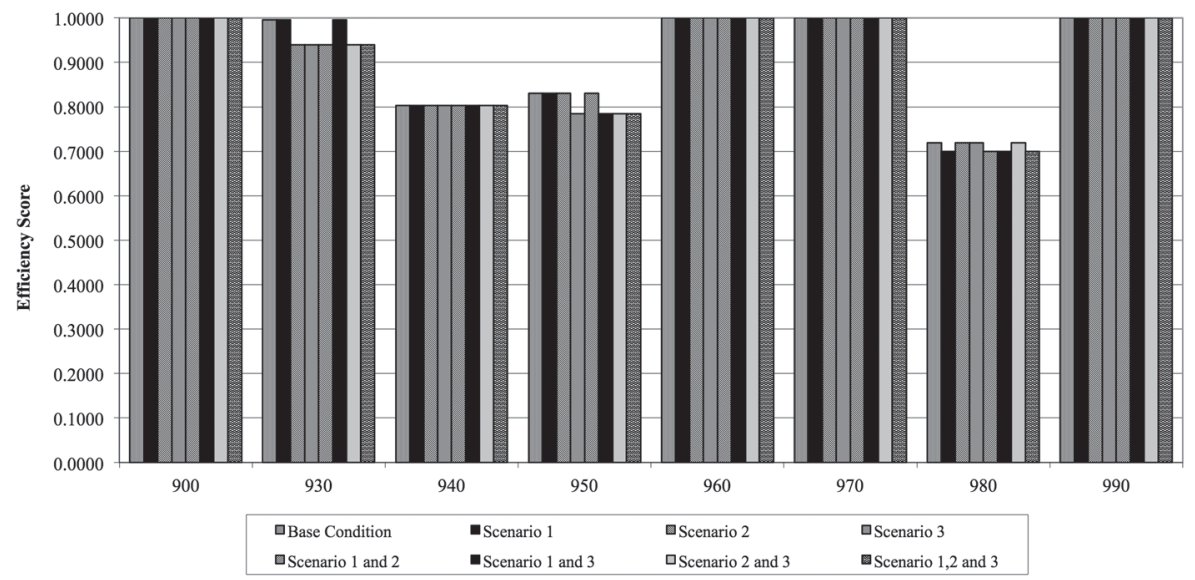

Figure 3. Efficiency scores of all scenarios for different routes

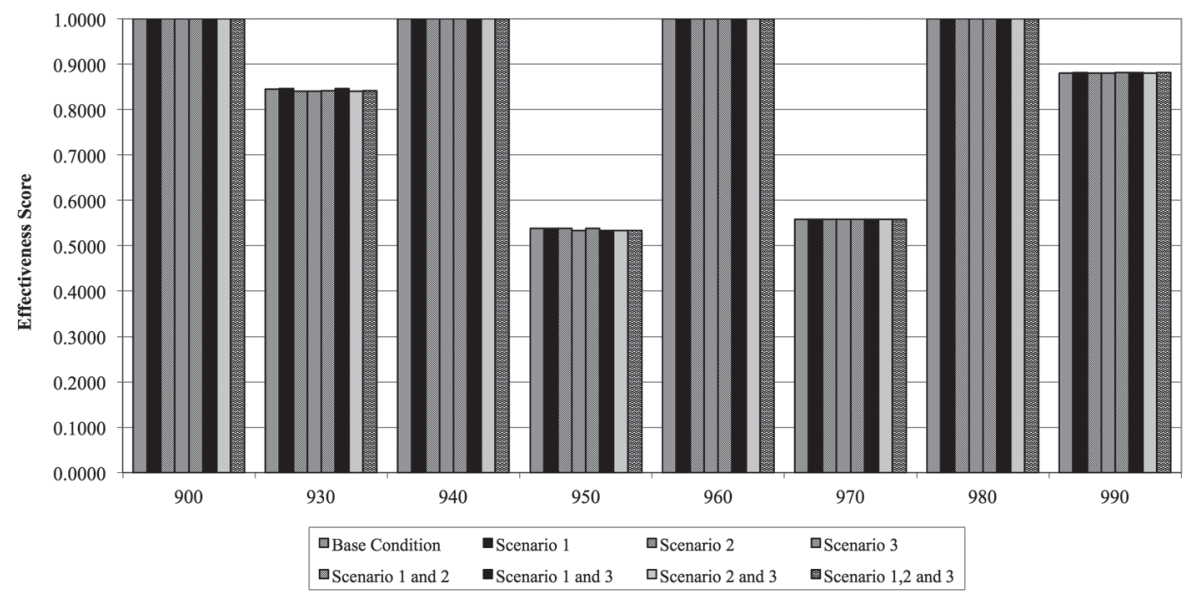

Figure 4. Effectiveness scores of all scenarios for different routes 


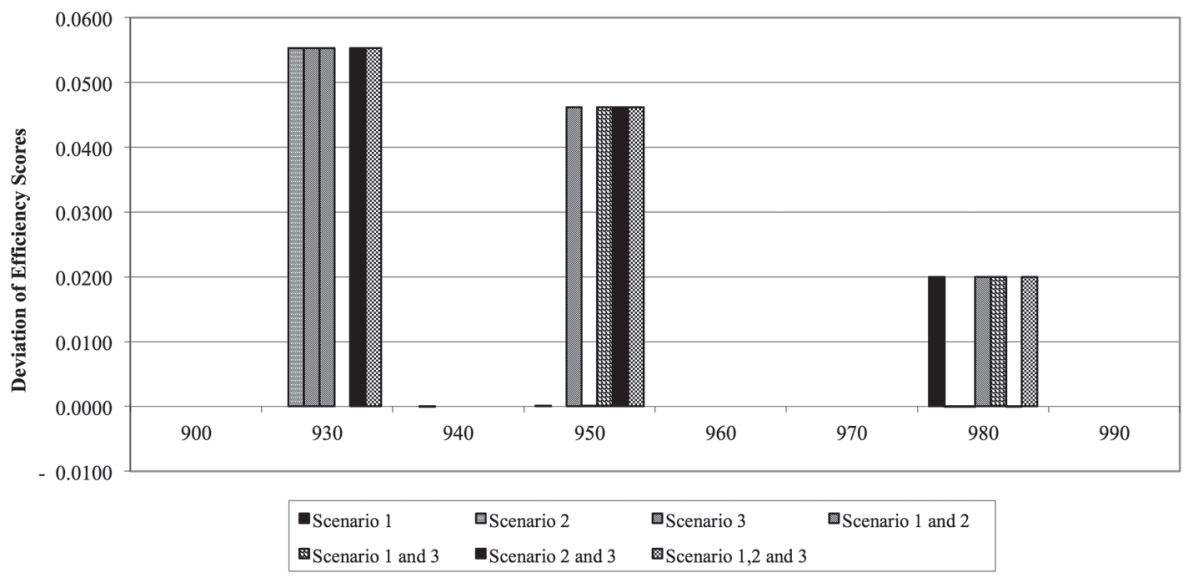

Figure 5. Deviation of efficiency scores of different scenarios for all routes

Figure 6 shows the deviation of effectiveness scores for all combinations of scenarios. It should be observed that the proposed changes to the service on routes 930 , 950 , and 980 (reducing the operating hours) have a slight impact on other routes' effectiveness. For example, routes 930,970 , and 990 are performing more effectively under some scenarios and less effectively under others. The effectiveness of route 980 was not affected by any of the scenarios. The effectiveness score is a relative term (as compared to other routes [DMUs]). As such, changing the input or output variables of one route may influence other routes' effectiveness measures.

The reason for the changes in routes 930,970 and 990 is that their reference or peer DMUs have greater influence on their performance level. That is, the output results of this DEA model indicate that the effectiveness score of route 970 is influenced by its reference or peer DMUs (namely, routes 940 and 980) with the proportions of 33.67 and 66.34 percent, respectively. On the other hand, the efficiency score of route 970 is not influenced by any other route (the efficiency score of route 970 is 1). This explains why scenario 1 (entailing changes to route 980) has affected the effectiveness score of route 970 and has not affected its efficiency scores. 


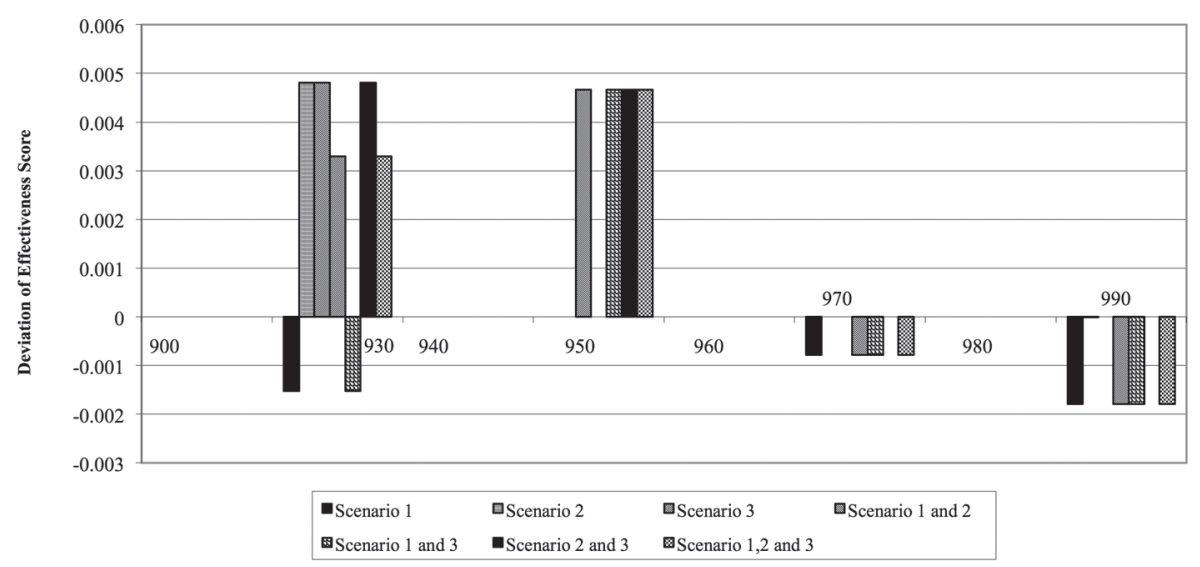

\section{Figure 6. Deviation of effectiveness scores of different scenarios for all routes from baseline condition}

It is evident from Figure 6 that scenario 1 results in the best effectiveness measures. However, it is to be noted that the other scenarios, although negatively affecting the effectiveness measures, may still be attractive scenarios, as they result in reduction of operating cost while only slightly affecting effectiveness. For example, the combined scenario $(1,2$, and 3 ) may be quite attractive, as it results in the lowest operating cost while only slightly affecting the effectiveness measures.

\section{Results and analysis of scenario for improving performance levels (route- splitting scenario)}

The DEA model was run again to estimate the efficiency and effectiveness scores of the bus routes for the route-splitting scenario. The efficiency and effectiveness scores for all routes (including the split routes) are shown in Figure 7.

The performance levels of all routes are summarized in the classification matrix form in Table 7. It is clearly evident from the table that the splitting-routes scenario resulted in improving the performance level for route 950 and for one part of route 930 (930B). Route 930A was performing efficiently but still ineffectively. The reason for such ineffectiveness might be the considerably low passenger demand on this part of the route. It is to be noted that some routes (e.g., route 900) were negatively affected by this scenario. The overall performance level of all routes was improved. As can be seen, no route was performing fairly efficiently and ineffectively. 


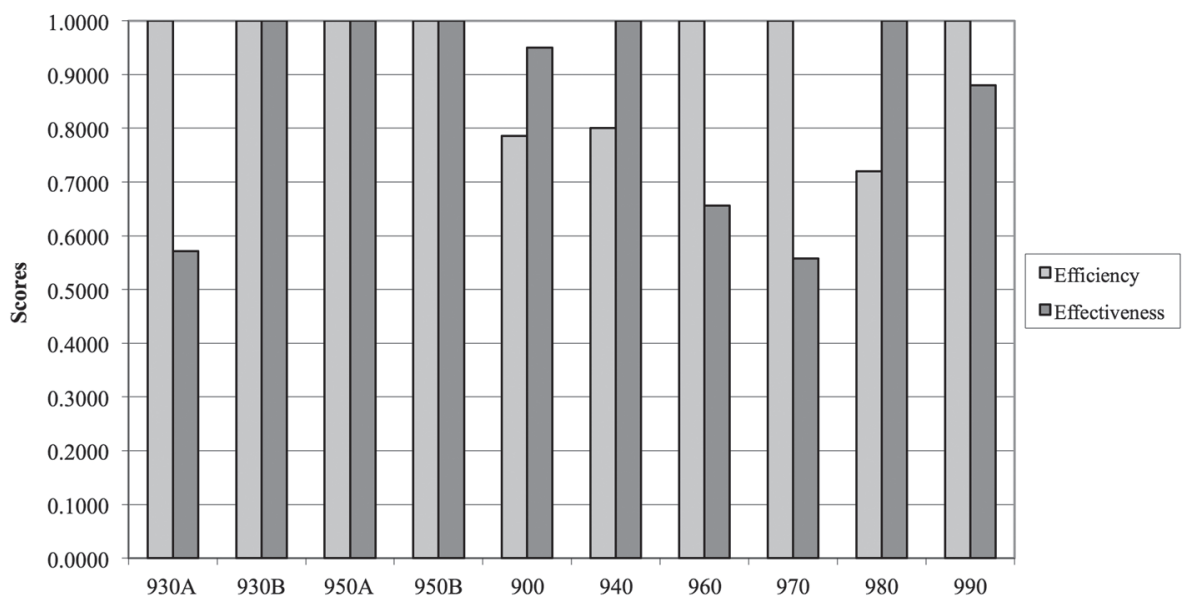

Figure 7. Efficiency and effectiveness scores for all routes for split route scenario

Table 7. Classification of Al Ain Bus Routes According to Efficiency and Effectiveness Scores (Route-Splitting Scenario)

\begin{tabular}{lccc}
\hline & Effective & Fairly Effective & Ineffective \\
\hline Efficient & $930 \mathrm{~B}$ & 960 & $930 \mathrm{~A}$ \\
& $950 \mathrm{~A}$ & 990 & 970 \\
& $950 \mathrm{~B}$ & & \\
\hline Fairly efficient & 940 & 900 & \\
& 980 & & - \\
\hline Inefficient & - & - & \\
\hline
\end{tabular}

\section{Conclusion}

In this paper, the efficiency and effectiveness of the Al Ain public bus service was measured and analyzed for different scenarios. The Data Envelopment Analysis (DEA) technique is very useful for measuring such efficiency and effectiveness in a situation when there is no historical data for bus service available to compare it with the current condition. The demonstrated scenarios indicated that strategies can be deployed to reduce operating hours with very little impact on the current efficiency and effectiveness measures. This may help the transit authority to cut operating cost or providing room for a better working environment for operators. 
Other scenarios to enhance service and increase the efficiency and effectiveness measures were also demonstrated. Such scenarios can be systematically and intuitively developed to enhance transit system performance in the city.

The study employed a limited number of input and output variables. Only four input and two output variables were used in the DEA model to measure performance levels. It should also be noted that no exogenous or environmental factors (factors that are not under management control) have been considered in this study. It is worth noting that some of the literature considered exogenous variables (e.g., Barnum et al. 2007, 2008). These exogenous variables were used to "adjust" the values of some of the output variables to the DEA model-for instance, the use of population and route characteristics variables to adjust "ridership" using a regression model (Barnum et al. 2008). It is true that the presented models did not account for exogenous variables, which may be regarded as a limitation, but, nonetheless, it is believed that the selected input and output variables were collected accurately, and, as such, the obtained efficiency measures are reasonably accurate. These efficiency scores are to be regarded as the true or managerial efficiencies (Barnum et al. 2008). Enriching the input database with more data on the actual operating and maintenance cost and incorporating the exogenous variables to adjust the true efficiency scores could have resulted in a more sound assessment of the system and more reliable model results. However, these data were not accurately available for use.

The practical benefits of this approach are evident. It can be used by the transit authority to assess the performance measures of its services, especially when only limited data are available. It can also be used to assess various strategies to enhance service. This paper has demonstrated through examples how the DEA model can be used to enhance the operating environment, reduce operating cost, and enhance the performance levels of the inefficient or ineffective routes.

Further extensions of this work entail enhancing individual route performance to meet multi-criteria objectives. In this paper, the efficiency and effectiveness measures were tackled individually. The strategies may entail risk; for instance, it may result in better efficiency but poor effectiveness, or vice versa. Another appealing approach would entail developing a generalized performance function, including various vehicle, operator, user, and safety performance measures with various weights. This generalized function could then represent the (output) basic measure to enhance system performance. Coupling such generalized performance functions with the DEA model would provide a good balance to satisfy the needs 
and safety requirements of users and yet take into consideration the operating constraints and resources.

\section{References}

Anderson, S. C., and G. L. Fielding. 1982. Comparative analysis of transit performance. Washington, D.C: Final Report, U.S. Department of Transportation.

Banker, R.D., A. Charnes, and W. W. Cooper. 1984. Some models of estimating technical and scale inefficiencies in data envelopment analysis. Management Science 9: 1078-1092.

Barnum, D.T., S. McNeil, and J. Hart. 2007. Comparing the efficiency of public transportation subunits using data envelopment analysis. Journal of Public Transportation 10(2).

Barnum, D.T., S. Tandon, and S. McNeil. 2008. Comparing the performance of bus routes after adjusting for the environment, using data envelopment analysis. Journal of Transportation Engineering 134(2): 59-109.

Benn, P.H. 1995. Bus route evaluation standards. TCRP Synthesis of Transit Practice 10: 1-63.

Benjamin, J., and K. Obeng. 1990. The effect of policy and background variables on total factor productivity for public transit. Transport Research B 24(1): 1-14.

Bly, P. H., and R. H. Oldfield. 1986. The effect of public transport subsidies on demand and supply. Transportation Research A 20(6): 415-427.

Boil'e, M.P. 2001. Estimating technical and scale inefficiencies of public transit systems. Journal of Transportation Engineering 127(3): 187-194.

Boschken, H. L. 2000. Behavior of urban public authorities operating in competitive markets. Administration and Society 31(6): 726-758.

Cervero, R. 1984. Cost and performance impacts of transit subsidy programs. Transportation Research A 18/5(6): 407-413.

Charnes, A., W. W. Cooper, and E. Rhodes. 1978. Measuring the efficiency of decision making units. European Journal of Operational Research 2: 429-444.

Chu, X., G. J. Fielding, and B. W. Lamar. 1992. Measuring transit performance using data envelopment analysis. Transportation Research A 3: 223-230. 
Cooper, W.W., L. M. Seiford, and J. Zhu. 2004. Handbook on Data Envelopment Analysis. Norwell, MA: Kluwer Academic Publishers.

Cowie, J., and D. Asenova. 1999. Organization form, scale effects and efficiency in the British bus industry. Transportation 26(3): 231-248.

De Borger, B., K. Kerstens, and A. Costa. 2002. Public transit performance. What does one learn from frontier studies? Transport Review 22(1): 1-38.

Emrouznejad, A. 2001. Ali Emrouznejad's DEA home page. Warwick Business School, Coventry CV47AL, U.K. Online [http://www.deazone.com]

Fare, R., S. Grosskopf, and C. A. K. Lovell. 1994. Production Frontiers. Cambridge, England: Cambridge University Press.

Farrell, M.J. 1957. The measurement of productive efficiency. Journal of the Royal Statistical Society A 120: 253-281.

Fielding, G. J., Glauthier, and C. A. Lave. 1978. Performance indicators for transit management. Transportation 7: 365-379.

Fielding, G. J., T. T. Babitsky, and M. E. Brenner. 1985. Performance evaluation for bus transit. Transportation Research Part A 19: 73-82.

Fielding, G. J. 1987. Managing Transit Strategically. San Fransisco, CA: Jossey-Bass Publishers.

Forkenbrock, D. J., and K. Dueker. 1979. Transit assistance allocation. Transport Research A 13 (5): 317-327.

Gilbert, G., and J. Dajani. 1975. Measuring the Performance of Transit Service. Chapel Hill, NY: University of North Carolina Press.

Karlaftis, M. G. 2004. A DEA approach for evaluating the efficiency and effectiveness of urban transit systems. European Journal of Operational Research 152: 154-164.

Karlaftis, M.G., J. S. Wasson, and E. S. Steadham. 1997. Impacts of privatization on the Performance of urban transit Systems. Transportation Quarterly 51(3): 67-79.

Kerstens, K. 1999. Decomposing technical efficiency and effectiveness of French urban transport. Annales d'Economie et de Statisque 54: 129-155. 
Lao, Y., and L. Liu. 2009. Performance evaluation of bus lines with data envelopment analysis and geographical information systems. Computers, Environment and Urban Systems 33: 247-255.

Meyer, J., and J. Gomez-lbanez. 1981. Autos, Transit and Cities. Cambridge, MA: Harvard University Press.

Nakanishi, Y. J., and J. R. Norsworthy. 2000. Assessing efficiency of transit service. IEEE Engineering Management Society (EMS '00) Proceedings, Albuquerque, MN, USA: 133-140.

Nash, A. 2006. Design of effective public transportation systems. 6th Swiss Transport Research Conference, Monte Verita, Ascona, Switzerland.

Odeck, J., and A. Alkadi. 2001. Evaluating efficiency in the Norwegian bus industry using data envelopment analysis. Transportation 28(3): 211-232.

Obeng, K., and G. A. Azam. 1995. Allocative distortions from transit subsidies. International Journal of Transport Economics 22(1): 15-34.

Park, V., and N. Kamp. 2004. Benchmark rankings for transit systems in the United States. Office of Research and Special Programs (RSPA), U.S. Department of Transportation, Washington, D.C. NCTR-527-03 FDOT-BC137-43.

Pina, V., and L. Torres. 2001. Analysis of the efficiency of local government services delivery. An application to urban public transport. Transportation Research Part A 35(10): 929-944.

Productivity Tools. 2005. Online [http://www.prodtools.com/home.html].

Pucher, J. 1982. A decade of change for mass transit. Transportation Research Record 858: 48-57.

RTTSRC (Roadway, Transportation and Traffic Safety Research Center). 2010. Assessment of public bus operation and services in the emirate of Abu Dhabi. Final Report. Department of Transport, Abu Dhabi.

Sanchez, G. 2009. Technical and scale efficiency in Spanish urban transport: Estimating with data envelopment analysis. Advances in Operations Research 2009: 1-16.

Sakano, R., K. Obeng, and G. A. Azam. 1997. Subsidies and inefficiency: Stochastic frontier approach. Contemporary Economic Policy 15(3): 113-127.1. 
Tomazinis, A. R. 1977. A study of efficiency indicators of urban public transportation systems. Final Report. U.S. Department of Transportation, Washington, D. C. DOT-TST-77-47.

Zhu, J. 2003. Quantitative Models for Performance Evaluation and Benchmarking: Data Envelopment Analysis with Spreadsheets And DEA Excel Solver. Norwell, MA: Kluwer Academic Publishers.

\section{About the Authors}

YASER. E.HAWAS (y.hawas@uaeu.ac.ae) currently is a professor in the Department of Civil and Environmental Engineering at United Arab Emirates University, where he also is Director of the RTTSRC. He obtained his Ph.D. from Civil Engineering Department at the University of Texas at Austin in 1996 and joined UAE University in 1998. He has published more than 50 international journal and conference papers and has carried out several professional studies and consultancy works for local and international agencies including the Texas Department of Transportation, the U.S. Federal Highway Administration, Holden Vehicle Manufacturers (Australia), the United Nations (ESCWA), and many others in the UAE.

MD. BAYZID KhAN (md_bayzid@uaeu.ac.ae) has a M.Sc. degree in Civil Engineering from United Arab Emirates University and is currently working as a research assistant at the RTTSRC at UAE University. He has a bachelor's degree in Urban and Regional Planning from Bangladesh University of Engineering and Technology and keen interest in GIS applications in transport planning and accident research and transport planning and policy.

NANDiTA BASU (nanditabasu@uaeu.ac.ae) has a master's degree in Urban and Regional Planning from Bangladesh University of Engineering and Technology and is currently working as a research assistant at the RTTSRC at UAE University. She completed her bachelor's degree in Urban and Regional Planning from Bangladesh University of Engineering and Technology and has a keen interest in GIS application in transport planning, land use, and public transportation. 